Moscow part of that survey was conducted by telephone at a time when there were 14 telephone lines for each 100 inhabitants in Moscow. That would hardly be classified as a random survey.

There are also some minor editorial slip-ups. The first secret elections were in 1988, when Gorbachev convened a special Party Conference, not the elections for the Party Congress, which were held in 1989. They also could have used a better indexer and editor. For example, they use much the same wording twice in criticizing a June, 1996 analysis of their reforms by a group of U.S. and Russian economists (pp. 18 and 94). They also repeat a statement by Chubais on pp. 151 and 160.

The reader will be rewarded, however, by their critique of how the Russian Central Bank and its senior officials set up a system of incentives that benefited them, not the state. The authors also skillfully answer the question, "Why is it that Moscow under Mayor Luzhkov prospered while the rest of the country suffered". In the same way, they provide a thoughtful analysis of how to go about implementing a more fruitful federal tax system.

There are important lessons to be learned from this book, some intended, some not. The intended lesson is that, on occasion, a study of stakeholders can be a useful approach to reform. The unintended lesson is that when they become consultants, academics can also become stakeholders. And when they look back at their past policy efforts, it is likely they will gloss what, in fact, others regard as seriously flawed.

\title{
The Land That Could Be: Environmentalism and Democracy in the Twenty-First Century, by William A. Shutkin. Cambridge, MA: The MIT Press (2000), xx, 273 pp.
}

\author{
Reviewed by Stella Capek, Division of Social Sciences, Hendricks College
}

Shutkin offers us a bravely optimistic, conceptually interesting and empirically well-grounded book that is a welcome addition to the literature on sustainability. In a world where attention to the environment is often seen as a luxury that comes only after we take care of more essential things (such as economic growth and jobs) his book is a refreshing reminder that environment is inextricably linked to, and provides the experiential ground for, community, democracy, the economy, and social justice. Named for Langston Hughes' visionary poem "The Land That Could Be" ("O let America be America again, The land that never has been yet And yet must be...."), Shutkin's book provides a kind of road map for healing the damage both to environment and to democracy in the United States. Built around a discussion of the concept of "civic environmentalism," it offers insights from four widely dispersed case studies: The urban agriculture experiments of the Dudley neighborhood in Roxbury, Massachusetts; the Fruitvale Transit Village in Oakland, California; conservation-based development in rural Routt County, Colorado, and "smart growth" initiatives in suburban New Jersey. Indeed, one of the book's strengths is the ease with which the author moves across the boundaries between landscapes that are urban, suburban, and rural, finding common ground through an exploration of the relationship between democracy and environmentalism. Another strength is the range of voices incorporated into the book, from interviews with residents to policy documents. Striking a balance between realism and optimism, and enriched by the author's hands-on experience with organizations such as Alternatives for Community \& Environment and New Ecology, Inc., The Land That Could Be invites us to consider pragmatically what the next steps would be if we take seriously, as the author does, the relationship between a healthy democracy and a healthy environment.

The concept central to Shutkin's book, and the subject of a theoretically rich discussion in the first three chapters, is civic environmentalism. Shutkin did not invent this idea, but it undergoes a creative expansion in his text. It serves as the basis for his view that democracy and environmental protection are "mutually constitutive"; that is, both depend on a healthy set of civic practices that affirm public space, place-based experience, social capital, multiple stakeholders, systemic analysis, and ground-up construction of knowledge and policy rather than top-down expertise alone. Essential to both is a sense of common destiny rather than a disappearance into private and privatized worlds. While democracy and environment mirror each other, the environment is given primacy, since it is the ground for our experience. Thus Shutkin points out early in his discussion, "A central argument of this book is that part and parcel of [the] diminution of civic spirit and rise in economic and social inequality has been the deterioration of the American environment, both built and undeveloped." (p.3).

To clarify the "civic" in civic environmentalism, and to plumb the civic landscape of the United States, Shutkin presents us in Chapter 1 with a list of core indicators of civic health: social capital (loosely defined as citizens' participation, or social investment in their communities), political participation, racial equality, socioeconomic equality, and public investment. After pointing out that the United States is the only industrialized nation that does not monitor overall social progress (a telling fact in and of itself), Shutkin puts together evidence from a range of sources--among them Robert Putnam, Orlando Patterson, Robert Bellah, William Julius Wilson, 
Christopher Lasch, and Cornel West -- to conclude that national civic participation is on the wane. Growing inequalities and the disappearance of public space appear in many forms, whether through the rise of a professional "overclass," the pressures of global capitalism, privatization, different life chances based on race and ethnicity, or a commercialized (and at the same time not equally accessible) Internet culture.

Shutkin proceeds, in Chapter 2, to consider the environmental consequences of this civic decline. Drawing on Paul Hawken's concept of "natural capital" (natural resources and the "services" they provide for us) he observes that "In communities endowed with a substantial amount of social capital, we tend to see an equivalent amount of natural capital" (p.46). The author's discussion ranges freely from Thomas Jefferson and John Ruskin to Dolores Hayden and Carolyn Merchant as he spells out the symbiotic relationship between environment (place) and democracy (civic community practice). Chapter 2 includes an overview of the history of development and land use in the United States, our habits of production and consumption of energy, and the environmental consequences of our actions as measured by a variety of indicators. Citing environmental historian William Cronon - whose influence is felt throughout much of this book - Shutkin reminds us that "living in history means leaving marks on the world; the question is, what kind of marks?" (Cronon (1995), cited in Shutkin, p.73). Shutkin's composite picture of our "marks" on the landscape points to environmental (and therefore democratic) decline. Later, in his case studies, he will document a different set of practices that suggest a more hopeful direction for both.

A significant pleasure of reading Shutkin's book is the way in which he tells his story. Descriptions of nature and social practices are skillfully embedded in each other, a technique that is thoroughly consistent with his argument that the cultural and natural are inseparable. Thus we meet, in Chapter 2, Ailanthus altissimus, a tree which Shutkin tells us was introduced by Frederick Law Olmsted from China for use in New York's Central Park, and now "the ubiquitous tree of the inner city," "the indicator species of urban America" (p.80). Known also as the "tree of heaven," this tree survives where little else can grow. Shutkin invites us into a paradox: to admire the beauty and tenacity of the tree, and at the same time to grasp its significance as a sign for a toxic environment disproportionately imposed on inner-city communities of color. This image, close to a poetry of landscape that a reader senses in many of Shutkin's descriptions (see, for example, the account of the natural history of the Roxbury landscape in Massachusetts), points back into a knowledge of history, and forward into social action, allowing Shutkin to conclude that "environmentalism is a uniquely powerful and appropriate tool for creating the kind of communities most Americans strive for but few enjoy" (p.87).

In Chapter 3, "The Land That Could Be: American Environmentalism and the Pursuit of Sustainable Communities," we learn about the legacy of U.S. environmentalism, from the more mainstream "romanticprogressive tradition" that incorporates John Muir and Gifford Pinchot (albeit with significant tensions) to a marginalized grassroots tradition that has not been part of the official history of the movement. The latter encompasses the work of individuals such as Alice Hamilton, Jane Addams, Benton MacKaye, and others who worked in urban environments to improve the life chances of disadvantaged populations. The author finds in their important efforts the precursor of the modern environmental justice movement. Further into the chapter, Shutkin offers us an explanation and critique of the existing environmental protection system in the United States (the focus on control rather than prevention; the "dense professional culture and specialized discourses" [p.100]; the tendency to address one substance at a time rather than an integrated, life-cycle view; and the dependence upon the courts). At the same time, he shows us -- and this is one of the book's strengths -- where the terrain is shifting or being "reinvented" in a direction that appears more consistent with civic environmentalism. This might involve cuttingedge technological designs such as eco-industrial parks or merely the ability of a new variety of stakeholders to work together to create "social capital."

The author's insistence upon including issues of environmental justice also greatly enhances his book, since this is a theme that is often conspicuously missing in the sustainability literature. Thus he can show us, drawing on the work of sociologist Robert Bullard and interviews with South Bronx environmental activist Vernice Miller, how environmental protection and economic development can go hand in hand, if the design is appropriate. In Chapter 3 , Shutkin also lays out for us the core components of civic environmentalism: 1) participatory process (including faceto-face democracy among a variety of stakeholders); 2) community and regional planning (which should incorporate a good understanding of a community's "assets"; 3 ) environmental education (all citizens and agencies should be expected to possess a bare minimum of environmental literacy, and science must be disseminated in an intelligible way); 4) industrial ecology (the new field of environmental and economic policy that rests on an integrated, comprehensive, full-cost accounting approach); 5) environmental justice (a focus on the socially just distribution of environmental impacts and citizen control over health and environment); and 6) place ("the physical, social, and emotional space that nurtures us as individuals and members of a community and is an animating force for civic engagement" [p.140]). In future chapters, this framework is used as a touchstone in each of the case studies.

In Chapters 4-7, we arrive at the case studies themselves. Each of these is compelling in its own way, since this is where theory meets practice. The forms in which we encounter civic environmentalism vary greatly, although all are consistent with the core elements identified above. In the Dudley area, a neighborhood scarred by redlining, white flight, landlord-initiated arson, and widespread toxic dumping, community groups find the means to create social capital through community redesign that includes urban agriculture. In the Fruitvale area of Oakland, a lowincome community carved up by freeways and blighted by urban pollution and the outflow of funds to the suburbs 
organizes to lay claim to public transportation and economic development by designing a "transit-oriented development" in the heart of the neighborhood. In Routt County, Colorado, two often-estranged groups, cattle ranchers and environmentalists, join forces to protect open land and to support conservation-based development (negotiating together what this might mean). In suburban New Jersey, local groups focus on protecting open space and managing growth, recapturing the legacy of the "Garden State" in the face of pressures toward sprawl.

Each of these scenarios contains a different combination of private and public investment, stakeholders, sustainable technology, and creative imagination. Each generates possible models for use elsewhere -- for example, the environmental indicators developed by the Trenton-based group New Jersey Future, or the concept of sustainable "working landscapes" negotiated by cattle ranchers and environmentalists, and increasingly adopted, Shutkin tells us, by mainstream environmental groups such as The Nature Conservancy. Some, like the first two cases, have a strong base in civil rights issues, and provide models for environmental justice in communities of color facing such challenges as "brownfield" redevelopment and urban disinvestment. All illustrate what Shutkin terms "an ecosystem approach to social problem solving, with the environment as both a prime subject and a principal metaphor of civic action" (p.238). The case studies make for exciting reading and allow Shutkin to elegantly present a case for civic environmentalism.

There is little to find fault with in this volume. Although it wasn't the case for this reader, some may find it a bit of a long ride getting to the case studies themselves, due to the length of the preceding chapters. Some additional references to civic environmentalism in the southern region of the country might be helpful, since this has been the originating place of the contemporary environmental justice movement and the setting for some interesting experiments with civic democracy--the city of Chattanooga comes to mind. Some will say that Shutkin is too optimistic. While he understandably focuses on the creative synergy that emerges in the communities presented here, those same communities are hugely vulnerable to a global capitalism that undermines social capital. Shutkin does not ignore these challenges, but chooses to put his energy elsewhere. Perhaps he too readily dismisses critics of "smart growth" who say that our addiction to growth is one of our most fundamental social problems. However, Shutkin stakes out his position (cautiously but energetically) among the optimists, supported by the experience that he has accumulated and shared with his readers. Let us hope that he is right that civic environmentalism will fulfill "environmentalism's promise as democracy's boldest symbol and practice" (p.244). By writing a book such as this one, he contributes to the likelihood of that outcome.

\section{References Cited:}

Cronon, William.

1995. Uncommon Ground: Toward Reinventing Nature. New York: Norton.

\section{Feeding the World: A Challenge for the Twenty-First Century. By Vaclav Smil. Cambridge, MA: The MIT Press (2000), xxviii, 360 pp.}

\section{Reviewed by Dr. Vijoy S. Sahay, Department of Anthropology, University of Allahabad, Allahabad ® 211002 (India).}

Whether in Ethiopia or the state of Orissa in India, all around the world, millions of people every year die of starvation, and suffer from malnutrition and under-nourishment. In many parts of the globe, because of either of floods or droughts, the production of food grain is damaged beyond recuperation every year. Moreover, the population growth continues with greater speed than ever before. Overwhelming concern with this situation has plagued the minds of the scientists, politicians, policy makers and planners, and even nonprofessionals, whose discourse on this subject often suggests that doomsday has arrived! After all, can the world possibly feed over ten billion people in the twenty-first century?

At such a juncture, and at the very threshold of the new millennium, Vaclav Smil's Feeding The World appears as a welcome relief. It comes up with convincing answers to many of the questions that have, hitherto, remained unanswered. It presents a more hopeful picture and suggests that if efforts are made in the right direction, the future of humanity is not bleak at all; instead, it is bright and encouraging. Above all, Smil's aspirations are based not on fancy but on facts with comprehensive and quality scientific data.

Feeding The World is a rare example of rational and logical interpretation of a huge mass of scientific data. Instead of answering the question of how many people the Earth can feed in the twenty-first century, Smil has rightly chosen a more practical, and a more meaningful inquiry to look into the best means of securing the requisite 